\title{
INNOVATIVE SPONGE-BASED MOVING BED-OSMOTIC MEMBRANE \\ 2 BIOREACTOR HYBRID SYSTEM USING A NEW CLASS OF DRAW SOLUTION \\ 3 FOR MUNICIPAL WASTEWATER TREATMENT
}

4

5

6

7

8

9

10

11

12

13

14

15

16

17

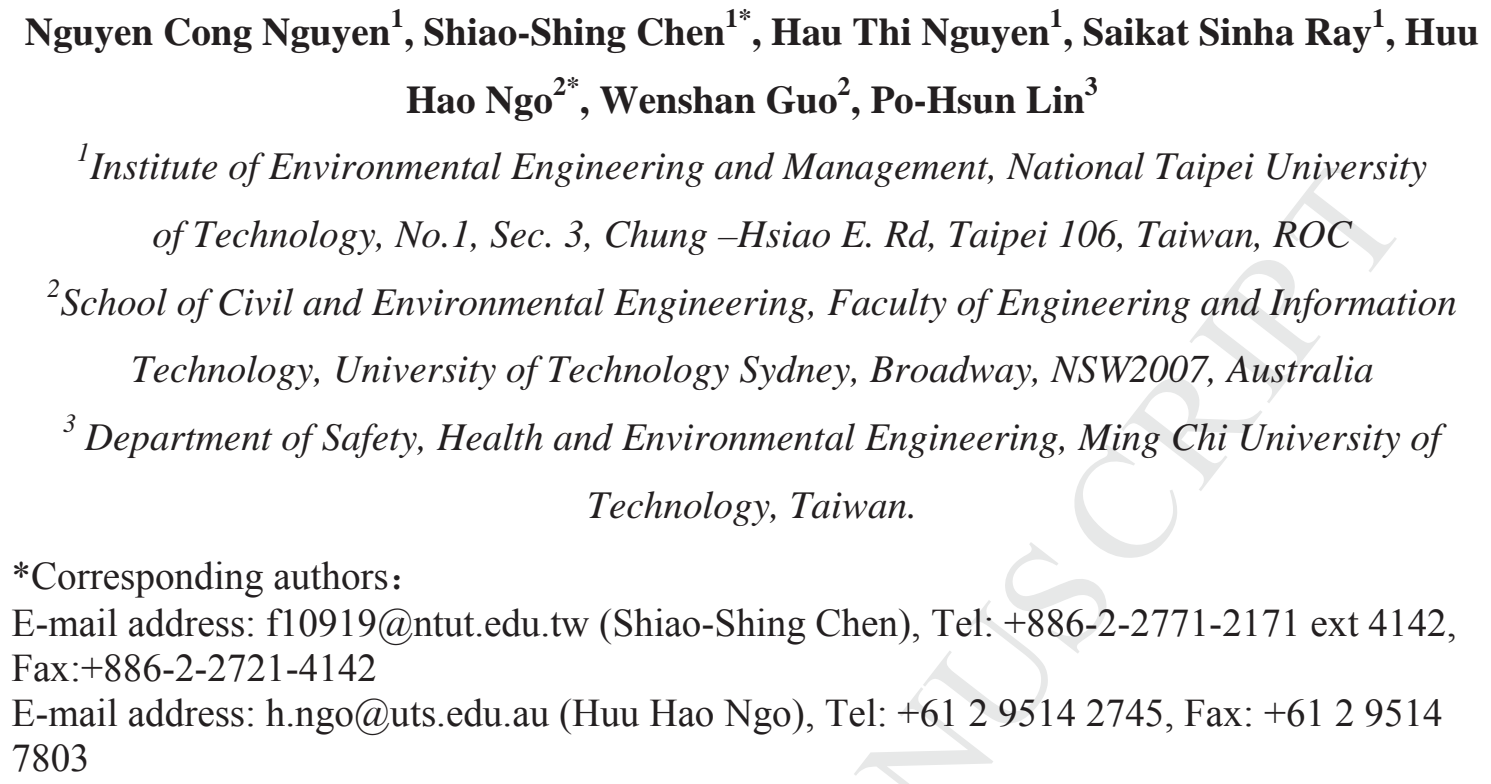

\section{Abstract}

For the first time, an innovative concept of combining sponge-based moving bed (SMB) and an osmotic membrane bioreactor (OsMBR), known as the SMB-OsMBR hybrid system, were investigated using Triton X-114 surfactant coupled with $\mathrm{MgCl}_{2}$ salt as the draw solution. Compared to traditional activated sludge OsMBR, the SMB-OsMBR system was able to remove more nutrients due to the thick-biofilm layer on sponge carriers. Subsequently less membrane fouling was observed during the wastewater treatment process. A water flux of $11.38 \mathrm{~L} /\left(\mathrm{m}^{2} \mathrm{~h}\right)$ and a negligible reverse salt flux were documented when deionized water served as the feed solution and a mixture of $1.5 \mathrm{M} \mathrm{MgCl}_{2}$ and $1.5 \mathrm{mM}$ Triton X-114 was used as the draw solution. The SMB-OsMBR hybrid system indicated that a stable water flux of $10.5 \mathrm{~L} /\left(\mathrm{m}^{2} \mathrm{~h}\right)$ and low salt accumulation were achieved in a 90 -day operation. Moreover, the nutrient removal efficiency of the proposed system was close to $100 \%$, confirming the effectiveness of simultaneous nitrification and denitrification in the biofilm layer on sponge carriers. The overall performance of the SMB-OsMBR hybrid system using $\mathrm{MgCl}_{2}$ coupled with Triton X-114 as the draw solution demonstrates its potential application in wastewater treatment. 


\section{ACCEPTED MANUSCRIPT}

Keywords: osmotic membrane bioreactor; forward osmosis; draw solution; sponge; carrier; moving bed.

\section{Introduction}

Advances in wastewater treatment technology have facilitated increasing the pollutant removal efficiency and meeting stringent effluent regulations. However, there are still many challenges faced in wastewater treatment processes, especially in relation to nutrient and trace organic removal, which necessitate improving existing wastewater treatment processes for achieving higher removal efficiency (Sayi-Ucar et al. 2015). Currently, membrane technology is employed to augment water supplies, and it is crucial for sustainable water production. Among the membrane processes, membrane bioreactor (MBR) technology has become one of the most effective options for improving water sustainability; this technology encourages wastewater reuse, requires less space and produces less sludge (Guo et al. 2012, Ramesh et al. 2006). However, conventional activated sludge-based MBRs pose operational and R\&D problems such as membrane fouling, high energy consumption, and limited nutrient removal capability (Nguyen et al. 2012).

To overcome these problems, a novel osmotic membrane bioreactor (OsMBR) with the following unique features was developed: (i) osmotic pressure is used as the driving force instead of hydraulic pressure, (ii) forward osmosis (FO) membranes show high rejection for a wide range of contaminants, and (iii) the membranes have a low fouling tendency (Cornelissen et al. 2011, Gwak et al. 2015, Qiu and Ting 2014, Tan et al. 2015). Nevertheless, a major technical challenge to OsMBR application was the lack of appropriate draw solutions that could reduce salt accumulation and membrane fouling during long-term operation (Ge et al. 2012, Kim 2014). Yap et al. (2012) demonstrated that the reverse salt flux from the draw solution into the bioreactor and the high salt rejection by the FO membrane caused the buildup of salinity in the bioreactor. Increased bioreactor salinity can severely impact on microbial viability and membrane performance because some functional bacteria are more sensitive to high salinity conditions (Moussa et al. 2006, Osaka et al. 2008). Kinetics studies have suggested that nitrogen and phosphorus removal efficiency dropped to $20 \%$ and $62 \%$, respectively, when salt concentration was $5 \% \mathrm{NaCl}$ in the bioreactor (Dinçer and Kargi 2001, Uygur and Kargi 2004). In addition, the salinity stress enhanced the release of both soluble microbial products and extracellular polymeric substances, leading to severe membrane fouling (Park et al. 2015). 
can reduce the osmotic pressure difference across the FO membrane, causing the water flux to decrease rapidly (Uygur 2006, Ye et al. 2009). For example, Holloway et al. (2014) used $\mathrm{NaCl}$ salt as the draw solution in an OsMBR system with mixed liquor suspended solids (MLSS) of $5 \mathrm{~g} / \mathrm{L}$ and achieved high removal efficiencies for phosphate and chemical oxygen demand $(96 \%)$ for a high water flux $\left(5.72 \mathrm{~L} /\left(\mathrm{m}^{2} \mathrm{~h}\right)\right)$. However, because monovalent ions $\left(\mathrm{Na}^{+}\right.$ with a hydrated radius of $0.18 \mathrm{~nm}$ and $\mathrm{Cl}^{-}$with a hydrated radius of $0.19 \mathrm{~nm}$ (Kiriukhin and Collins 2002)) could easily pass through the FO membrane (membrane pore size: $0.37 \mathrm{~nm}$ ) (Xie et al. 2012 (a)), the TDS concentration in the bioreactor increased by approximately 8 g/L after 40 days (Holloway et al. 2014). To minimize salt leakage, Qiu and Ting (2013) demonstrated that using a divalent salt such as $\mathrm{MgCl}_{2}\left(\mathrm{Mg}^{2+}\right.$ with a hydrated radius of $0.3 \mathrm{~nm}$ (Kiriukhin and Collins 2002)) in the draw solution in a submerged OsMBR could help increase organic matter removal to $98 \%$ and reduce salt leakage compared with an $\mathrm{NaCl}$ draw solution. However, the mixed liquor conductivity in the OsMBR was still high, ranging from 2 to $17 \mathrm{mS} / \mathrm{cm}$ for a 80-day operation, because of the reverse transport of $\mathrm{MgCl}_{2}$ from the draw solution and the rejection of dissolved solutes in the feed by the FO membrane.

A mixture of Ethylenediaminetetraacetic acid disodium salt (EDTA-2Na) and Triton X-100 was used as the draw solution in an OsMBR in our previous study. Although it can reduce the reverse salt flux appreciably and minimize salt accumulation in the bioreactor for a 60-day operation (Nguyen et al. 2015a), the water flux was relatively low because of the limited solubility of EDTA-2Na salt in water. Meanwhile, the solubility of $\mathrm{MgCl}_{2}$ is high (up to $5 \mathrm{M}$ ) so as it can produce a high osmotic pressure and high water flux. Therefore, to achieve a high water flux and minimal salt leakage, a mixture of Polyethylene glycol tert-octylphenyl ether (Triton X-114) and $\mathrm{MgCl}_{2}$ was used as the draw solution in the current study. The advantage of using the non-ionic Triton X-114 surfactant is that it has a large structure involving a long straight carbon chain and a low critical micelle concentration (CMC) of $0.2 \mathrm{mM}$. This structure leads to the formation of second layers on the membrane surface, constricting the membrane pores and minimizing reverse salt diffusion. Moreover, the high water solubility of $\mathrm{MgCl}_{2}$ can produce high osmotic pressure as well as a high water flux in an OsMBR system.

Up to this date, the major technical challenges to OsMBR application are the build-up of salinity in the bioreactor, the membrane fouling in long-term operation and limited nutrient removal in single reactor, which motivated the author to carry out this work. To the best of 
our knowledge, a draw solution containing a mixture of Triton X-114 surfactant and $\mathrm{MgCl}_{2}$

salt has not been used for a sponge-based moving bed (SMB)-OsMBR hybrid system to simultaneously achieve a low salt accumulation, a low fouling and high nutrient removal efficiency. Hence, this study systematically investigated the performance of the mixture as the draw solution in an SMB-OsMBR system for municipal wastewater treatment. First, the effect of the Triton X-114 concentration on the water flux and reverse salt flux was evaluated using deionized (DI) water as the feed solution. Next, the variation of the water flux and amount of salt accumulation with the operating duration was examined using synthetic wastewater as the feed solution. The nutrient removal efficiency was then determined in the SMB-OsMBR hybrid system for the proposed draw solution. Finally, the membrane fouling characteristics were analyzed using scanning electron microscopy and energy dispersive $\mathrm{x}$-ray spectroscopy (SEM-EDS), and fluorescence excitation-emission matrix (FEEM) spectrophotometry.

\section{Materials and methods}

\subsection{Description of SMB-OsMBR}

A laboratory scale SMB-OsMBR system is shown in Figure 1. The FO module with an effective membrane area of $120 \mathrm{~cm}^{2}$ was fabricated with a tube configuration and wrapped in OsMem $^{\mathrm{TM}}$ cellulose triacetate with embedded polyester screen support (CTA-ES) flat sheet membranes (Hydration Technologies, Inc., Albany, OR, USA). It was then immersed in the vertical position in the bioreactor tank $(6 \mathrm{~L})$, with the active layer of the membrane facing the feed solution. Sponge biocarriers (Table 1) were added to the bioreactor tank after acclimatization, with a filling rate of $40 \%$ (by volume of the bioreactor). Air diffusers were installed at the bottom of the bioreactor for moving the biocarriers and reducing membrane fouling. In the SMB-OsMBR system, synthetic wastewater was continuously pumped into the bioreactor tank from a feed tank $(6 \mathrm{~L})$, and the liquid level in the bioreactor tank was maintained at a constant level by connecting the overflow pipe to the feed tank. The hydraulic retention time (HRT) was determined by the SMB-OsMBR water flux and was in the range of $40-51 \mathrm{~h}$.

The draw solution was pumped into the FO membrane tube and this caused water from the feed solution to permeate through the membrane to dilute the draw solution. Constantly maintaining the draw solution concentration was achieved by using a conductivity controller connected to a concentrated draw solution reservoir. The feed tank was placed on a digital scale (BW12KH, Shimadzu, Japan), and the water flux was calculated according to changes in the feed tank weight.

\section{Table 1}


136 Specifications of sponge carrier used in the SMB-OsMBR system.

\begin{tabular}{lll}
\hline Factor & Unit & Value/material \\
\hline Shape & - & Cubic $(1 \times 1 \times 1 \mathrm{~cm})$ \\
Density & $\mathrm{kg} / \mathrm{m}^{3}$ & $28-30$ \\
Tensile strength & $\mathrm{kPa}$ & 150 \\
Specific Surface area & $\left(\mathrm{cm}^{2} / \mathrm{g}\right)$ & 0.91 \\
Weight (10 pieces) & $\mathrm{g}$ & 0.51 \\
Biomass attached on media (after 60 & $(\mathrm{g}$ biomass/g sponge) & 1.16 \\
days) & & \\
\hline
\end{tabular}

137

The amount of salt accumulation in the bioreactor was determined by monitoring the conductivity of the mixed liquor with a conductivity meter (Oakton Instruments, USA). The fluctuation in the room temperature during the experiment was in the $26-29^{\circ} \mathrm{C}$ range. Samples were collected from the bioreactor and draw solution tank for measuring the dissolved organic carbon, $\mathrm{NH}_{4}{ }^{+}-\mathrm{N}, \mathrm{NO}_{3}{ }^{-}-\mathrm{N}, \mathrm{NO}_{2}{ }^{-}-\mathrm{N}$, and $\mathrm{PO}_{4}{ }^{3-}-\mathrm{P}$. Throughout SMB-OsMBR operation, 200 $\mathrm{mL}$ of mixed liquor was withdrawn daily (every $24 \mathrm{~h}$ ) from the bioreactor and allowed to settle for $30 \mathrm{~min}$. The clarified supernatant was discarded. Water from the mixed liquor was used as a sample for analysis. h.

\subsection{Feed and draw solutions}

Synthetic wastewater simulating domestic wastewater served as the inoculum for the sponge carriers and as the feed solution for the SMB-OsMBR. It contained glucose, ammonium chloride, potassium phosphate, trace elements as shown in Table S1, which has $150 \pm 8 \mathrm{mg} / \mathrm{L}$ dissolved organic carbon (DOC), $30 \pm 2 \mathrm{mg} / \mathrm{L} \mathrm{NH}_{4}{ }^{+}-\mathrm{N}$, and $6 \pm 1 \mathrm{mg} / \mathrm{L} \mathrm{PO}_{4}{ }^{3-}-\mathrm{P}$. In addition, deionized (DI) water was used as the feed solution to determine the reverse salt flux. $\mathrm{MgCl}_{2}$ was purchased from Imperial Chemical Corp, Taiwan. Triton X-114 with a CMC of $0.2 \mathrm{mM}$ was supplied by Scharlau Chemise, Spain. The draw solution was prepared using $\mathrm{MgCl}_{2}$ and the Triton X-114 surfactant at molar ratios of 3000:1, 1500:1, 1000:1, and 600:1 at room temperature. Prior to being used in the FO tests the mixtures were continuously stirred for 48 
$174 J_{w}=\frac{\Delta V}{A \Delta t}$

where $\Delta V$ is the total increase in the volume of the permeate water (L) collected over a

\section{ACCEPTED MANUSCRIPT}

The CTA-ES FO membrane used in this study was supplied by Hydration Technology Innovations (OsMem ${ }^{\mathrm{TM}}$ CTA Membrane 130806, Albany, OR, USA). The overall thickness of the membrane was approximately $50 \mu \mathrm{m}$, and the membrane was negatively charged at a $\mathrm{pH}$ greater than 4.5 (Xie et al. 2012(b)). The contact angle of the membrane was determined to be approximately $73^{\circ}$ as shown in Figure S1. This result is in agreement with Jin et al. (2012) and Xie et al. (2012(b)), who observed that the FO membrane is moderately hydrophobic with a contact angle of $60^{\circ}-80^{\circ}$.

\subsection{Measurement of water flux and reverse salt flux}

The experimental water flux $\mathrm{J}_{\mathrm{w}}\left(L / \mathrm{m}^{2} \mathrm{~h}\right)$ was calculated by measuring the change in the feed tank weight with time as follows: predetermined period, $\Delta \mathrm{t}(\mathrm{h})$ and $\mathrm{A}$ is the effective FO membrane area $\left(\mathrm{m}^{2}\right)$. The reverse salt flux $J_{S}\left(\mathrm{~g} / \mathrm{m}^{2} \mathrm{~h}\right)$ of the draw solution was determined from the amount of salt accumulation in the feed tank:

$$
J_{s}=\frac{V_{t} C_{t}-V_{0} C_{0}}{A t}
$$

where $C_{\mathrm{t}}$ and $V_{\mathrm{t}}$ are the concentration and volume of the feed solution measured at time $t$, respectively, and $C_{0}$ and $V_{0}$ are the initial concentration and initial volume of the feed solution, respectively.

The specific reverse salt flux $\left(J_{S} / J_{w}, \mathrm{~g} / \mathrm{L}\right)$ is defined here as the ratio of salt $\left(J_{s}, \mathrm{~g} / \mathrm{m}^{2} \mathrm{~h}\right)$ in the reverse direction to the water flux $\left(J_{w}, \mathrm{~L} / \mathrm{m}^{2} \mathrm{~h}\right)$ in the forward direction, and it is used to estimate the amount of draw solute lost per liter of water produced during FO.

\subsection{Analytical methods}

Samples used for DOC analysis were first filtered using $0.45 \mu \mathrm{m}$ filter paper and then analyzed using a total organic carbon analyzer (Aurora 1010C, O.I. Analytical Corporation, USA). The $\mathrm{pH}$ and dissolved oxygen (DO) in the bioreactor were measured every day using a pH meter (HI 9025, Hanna Instruments) and DO meter (OM-51E, HORIBA Ltd., Japan), respectively. The concentrations of $\mathrm{PO}_{4}{ }^{3-}-\mathrm{P}, \mathrm{NO}_{3}{ }^{-}-\mathrm{N}, \mathrm{NO}_{2}{ }^{-}-\mathrm{N}$, and $\mathrm{NH}_{4}{ }^{+}-\mathrm{N}$ were analyzed using ion chromatography (ICS-90, Dionex, USA) and an ultraviolet-visible 
spectrophotometer (DR-4000, Hach, Japan). The osmolality of draw solutions was measured using an osmometer (Model 3320, Advanced Instruments, Inc., USA). The measured osmolality of the solutions was then converted to osmotic pressure by using the Morse equation as follows:

$\pi=(\Sigma \phi n C) R T$

where, $(\Sigma \phi n C)$ represents total osmolality, $R$ is the universal gas constant, and $T$ is the absolute temperature.

The viscosity and conductivity were determined using the Vibro Viscometer (AD Company, Japan) and a conductivity meter (Sension156, Hach, China), respectively. The contact angle of the FO membrane was measured by CAM 100 (KSV Instruments Inc., USA). The fouled membranes were observed and examined using SEM-EDS (JSM-5600, JEOL, Tokyo, Japan). FEEM spectrophotometry analyses were performed on samples of the diluted draw solution and bioreactor feed. Extracellular polymeric substances (EPS) and soluble microbial products (SMP) were extracted and quantified by measuring the polysaccharide and protein concentrations. Polysaccharide concentration was measured by method established by Dubois et al. (1956) using glucose as the standard. Protein concentration was determined following the method of Bradford (1976) using bovine serum albumin as the protein standard.

\section{Results and discussion}

\subsection{Effect of surfactant concentration on water flux and reverse salt flux}

Figure 2 shows the reverse salt fluxes and water fluxes for five draw solutions with various Triton X-114 concentrations and a fixed $\mathrm{MgCl}_{2}$ concentration of $1.5 \mathrm{M}$. FO experiments were conducted with the active layer of the membrane facing the feed solution, which was DI water. The reverse flux decreased considerably when Triton X-114 with concentrations ranging from 0.5 to $2.5 \mathrm{mM}$ was coupled with the $\mathrm{MgCl}_{2}$ draw solution. Figure 2 indicates that higher concentrations of Triton X-114 coupled with the $\mathrm{MgCl}_{2}$ draw solution led to a lower reverse salt flux. For example, $J_{s}$ decreased from 3.28 to $2.01 \mathrm{~g} /\left(\mathrm{m}^{2} \mathrm{~h}\right)$ when Triton X114 with a concentration in the range $0.5-2.5 \mathrm{mM}$ was coupled with $1.5 \mathrm{M} \mathrm{MgCl}_{2}$ draw solution. Compared with pure $\operatorname{MgCl}_{2}\left(J_{s}=9.02 \mathrm{~g} /\left(\mathrm{m}^{2} \mathrm{~h}\right)\right), 1.5 \mathrm{M} \mathrm{MgCl}_{2}$ draw solution coupled with $1.5 \mathrm{mM}$ Triton $\mathrm{X}-114$ resulted in a lower reverse salt flux $\left(J_{s}=2.03 \mathrm{~g} /\left(\mathrm{m}^{2} \mathrm{~h}\right)\right)$. The reason is that when Triton $\mathrm{X}-114$ was coupled to the $\mathrm{MgCl}_{2}$ draw solution, the adsorption of Triton X-114 occurred on the membrane because of the hydrophobic interaction between the tails of Triton X-114 and the membrane. This constricted FO membrane pores substantially 

and reduced the reverse salt diffusion of $\mathrm{Mg}^{2+}$ and $\mathrm{Cl}$, as illustrated in Figure 3 (Nguyen et al. 2015a, Nguyen et al. 2015b). This phenomenon agrees with the observation by Kiso et al., that: firstly, the hydrophobic interactions between selected pharmaceuticals and CTA FO membranes were the dominant organic removal mechanism; and secondly, the hydrophobicity of the pharmaceuticals strongly influenced their rejection. Thus, increased hydrophobicity led to increased rejection (Jin et al. 2012, Kiso 1986).

The water flux decreased slightly when the concentration of Triton X-114 was increased from 0.5 to $2.5 \mathrm{mM}$ because of the rise in the draw solution's viscosity from 1.82 to $2.57 \mathrm{cp}$, which changed the diffusivity of water through the FO membrane (Table 2). Furthermore, a higher Triton X-114 concentrartion may cause more effective pore constriction of FO membrane, which subsequently decreased water flux. The optimal Triton X-114 concentration was 1.5 $\mathrm{mM}$, and at this concentration, a low reverse salt flux $\left(2.03 \mathrm{~g} /\left(\mathrm{m}^{2} \mathrm{~h}\right)\right)$, low specific reverse salt flux $(0.18 \mathrm{~g} / \mathrm{L})$, and relatively high water flux $\left(11.38 \mathrm{~L} /\left(\mathrm{m}^{2} \mathrm{~h}\right)\right)$ were simultaneously achieved.

[Figure 2]

\section{[Figure 3]}

\section{Table 2}

Osmotic pressure and viscosity of the draw solutions

\begin{tabular}{lcc}
\hline Draw solution & Osmotic pressure, bar & Viscosity, cp \\
\hline $1.5 \mathrm{M} \mathrm{MgCl}_{2}$ only & $107.48 \pm 1.24$ & $1.82 \pm 0.25$ \\
$1.5 \mathrm{M} \mathrm{MgCl}_{2}+0.5 \mathrm{mM}$ Triton X-114 & $108.60 \pm 2.48$ & $1.87 \pm 0.18$ \\
$1.5 \mathrm{M} \mathrm{MgCl}_{2}+1 \mathrm{mM}$ Triton X-114 & $109.34 \pm 1.26$ & $2.15 \pm 0.21$ \\
$1.5 \mathrm{M} \mathrm{MgCl}_{2}+1.5 \mathrm{mM}$ Triton X-114 & $110.75 \pm 2.98$ & $2.48 \pm 0.16$ \\
$1.5 \mathrm{M} \mathrm{MgCl}_{2}+2.5 \mathrm{mM}$ Triton X-114 & $111.20 \pm 3.10$ & $2.57 \pm 0.18$ \\
\hline
\end{tabular}

\subsection{Water flux and salt accumulation during SMB-OsMBR operation}

Acclimatized sponge cubes $(1 \mathrm{~cm} \times 1 \mathrm{~cm} \times 1 \mathrm{~cm})$ were used as the moving bed medium in the SMB-OsMBR hybrid system and microbial community attached to the sponge biocarrier as shown in Figure S2. Figure 4a shows the water flux as a function of time during the testing of the SMB-OsMBR hybrid system by using a mixture of $1.5 \mathrm{M} \mathrm{MgCl}_{2}$ and $1.5 \mathrm{mM}$ Triton X114 as the draw solution and the synthetic wastewater as the feed solution. The results show that the decrease in the water flux (from 11.30 to $9.83 \mathrm{~L} /\left(\mathrm{m}^{2} \mathrm{~h}\right)$ ) can be attributed to reduced 
. driving force and membrane fouling. Clearly, the driving force across the FO membranes decreased as the bioreactor salinity steadily increased, because of reverse salt flux (diffusion of salts from the draw solution to the bioreactor) and high FO rejection resulting from salts entering the bioreactor from the influent while the TDS of the draw solution remained constant between 100 to $110 \mathrm{~g} / \mathrm{L}$ (Figure $4 \mathrm{~b}$ ). However, a difference of approximately $11.49 \%$ was observed between the water flux measured on the first day $\left(11.30 \mathrm{~L} /\left(\mathrm{m}^{2} \mathrm{~h}\right)\right)$ and that measured on the 90th day $\left(9.83 \mathrm{~L} /\left(\mathrm{m}^{2} \mathrm{~h}\right)\right)$. As shown in Figure 5, most of the microorganisms were attached to the sponge carriers rather than the membrane, which prevented membrane fouling. Hence, the moderate decrease in the water flux suggested that membrane fouling in the SMB-OsMBR was not appreciable. Moreover, when the SMB-OsMBR system was used in the FO mode with the active layer of the membrane facing the wastewater, potential membrane foulants could be easily removed by the hydraulic shear force generated by aeration (Mi and Elimelech 2008) and the moving sponge. The experimental results also revealed that small fluctuations in the water flux occurred because of changes in the draw and feed solution temperature, as illustrated in Figure 4a (Cornelissen et al. 2011). The hydraulic retention time was determined by the SMB-OsMBR water flux and was in the range of 40-51 h.

Figure $4 \mathrm{~b}$ shows a plot of the salt accumulation in the bioreactor of the SMB-OsMBR system versus time. The results show that the TDS in the bioreactor increased gradually from 450 to $1525 \mathrm{mg} / \mathrm{L}$ after 90 days of operation. This increase results from the accumulation of salts from the influent wastewater as well as the solutes that have diffused through the membrane from the draw solution into the bioreactor (Lay et al. 2011, Xiao et al. 2011). However, the relatively low concentration $(<2 \mathrm{~g} / \mathrm{L})$ of the accumulated salt in the bioreactor enabled the normal growth of the microbial community due to the low specific reverse salt flux from the novel draw solution and daily withdrawn mixed liquor $(200 \mathrm{~mL})$ from the bioreactor. Thus, to prevent microbial activity inhibition, the maximum bioreactor tank salinity should not exceed $2 \mathrm{~g} / \mathrm{L}$ (Ye et al. 2009). As shown in Figure 4b, Triton X-114 coupled with $\mathrm{MgCl}_{2}$ as the draw solution in the SMB-OsMBR system obtained much lower salt accumulation $(<1.6 \mathrm{~g} / \mathrm{L})$ than that of using traditional draw solution ( $>8 \mathrm{~g} / \mathrm{L}$ ) (Holloway et al. 2014)), indicating a promising draw solution for future OsMBR application to overcome the effect of accumulated salinility on biological activity.

[Figure 4] 


\subsection{Nutrient rejection}

294 In the SMB-OsMBR system, an ideal attached-growth medium (sponge) serves as a mobile carrier for active biomass, reduces FO membrane fouling, and facilitates the removal of nitrogen and phosphorus in a single reactor. Figure 6 shows that the SMB-OsMBR system removed approximately $99 \%$ of $\mathrm{PO}_{4}{ }^{3-} \mathrm{P}$, which is higher than the removal efficiency of conventional activated sludge OsMBR (Holloway et al. 2014). A possible reason for the high percentage removal is that the small pore radius of the FO membrane $(0.37 \mathrm{~nm})$ caused all contaminants to be rejected because of the steric effect and electrostatic repulsion of the FO membrane. Furthermore, since only a negligible amount of biomass (MLSS of $200 \mathrm{mg} / \mathrm{L}$ in bioreactor) was detached from the sponge during the 90-day operation of the SMB-OsMBR system, the presence of phosphorus-accumulating organisms in forms of attached growth on sponge carriers led to increased removal of phosphorus (Bao et al. 2007, Guo et al. 2008). Figure 6 also illustrates that the SMB-OsMBR hybrid system consistently achieved complete $\mathrm{NH}_{4}{ }^{+}-\mathrm{N}$ removal (approximately 99.38\%); the average $\mathrm{NH}_{4}{ }^{+}-\mathrm{N}$ concentration of the effluent was $0.19 \mathrm{mg} / \mathrm{L}$. This finding accords with previous observations that the OsMBR system can remove large amounts of ammonium (Achilli et al. 2009, Holloway et al. 2014, Qiu and Ting 2014). This can be explained by most of the ammonium being converted into nitrite and nitrate in the nitrification process. Additionally, the high rejection of unconverted $\mathrm{NH}_{4}{ }^{+}-\mathrm{N}$ by the FO membrane also increased the ammonium removal efficiency. As shown in Figure 6, the entire SMB-OsMBR system could eliminate more than $75 \%$ of $\mathrm{NO}_{3}{ }^{-}-\mathrm{N}$ and $74 \%$ of $\mathrm{NO}_{2}{ }^{-}-$

\subsection{Membrane fouling}

SEM observations showed that compared with the original membrane, a thin gel-like fouling layer consisting of bacterial cells was attached to the active layer of the fouled membrane (Figures 7a, b). This observation concurs with that of Zhang et al. (2012) who confirmed that extracellular polymeric substances of bacterial communities could be a crucial factor governing membrane fouling. However, the fouling layer on the FO membrane surface was very thin, and it had only a small effect on the water flux during 90-day SMB-OsMBR operation. An explanation for this observation is that the sponge's performance as a free active moving biocarrier in combination with the hydrodynamic shear force in the SMB- 

OsMBR system facilitated cleaning the FO tube membrane, resulting in reduced membrane fouling. Additionally, a thin layer of $\mathrm{MgCl}_{2}$ attached to the support layer surface of the used membrane caused membrane fouling because of concentration polarization, as shown in Figure 7c. This explanation is supported by the following observations: (i) the $\mathrm{MgCl}_{2}$ solution was in contact with the support layer and could easily attach to the FO membrane surface in the presence of reverse salt diffusion; and (ii) when the used membrane was dried at room temperature for $12 \mathrm{~h}$, a white salt layer was observed on the membrane surface.

Figure 8 shows a comparison of the FEEM spectra for the bioreactor feed and diluted draw solution on the same fluorescence intensity scale. The FEEM of the bioreactor feed sample shows peaks corresponding to protein-like substances (emission range 290-315 nm, excitation range $270-280 \mathrm{~nm}$ ), a humic-acid-like substance (emission range 420-430 nm, excitation range $315-335 \mathrm{~nm}$ ), and a fulvic-acid-like substance (emission range 365-445 nm, excitation range 230-245 nm). However, no peak was observed for the diluted draw solution sample. These results confirm that the FO membrane prevented soluble microbial by-productlike, fulvic acid-like, and humic acid-like substances in the bioreactor from being transported to the diluted draw solution. Moreover, the fouling layer on the FO membrane and the biofilm layer on a biocarrier were extracted for measuring EPS and SMP concentrations (Figure 9). The EPS content in the fouling layer on the FO membrane (24 mg/g MLSS) was much lower than that in the biofilm layer on a biocarrier ( $86 \mathrm{mg} / \mathrm{g}$ MLSS). The SMP content in the fouling layer on the FO membrane $(10.7 \mathrm{mg} / \mathrm{L})$ was also lower than that in the biofilm layer on a biocarrier $(46.5 \mathrm{mg} / \mathrm{L})$. The results from the SMP and EPS analysis combined with the FEEM spectrophotometry observations suggest that the polysacharides and protein-like substances were the main components that accumulated on the active layer of the used membrane, causing fouling of the FO membrane. Previously, these foulants have been identified as essential agents in MBR and OsMBR systems (Valladares Linares et al. 2012, Wang and Li 2008, Zhang et al. 2012).

[Figure 7]

[Figure 8]

[Figure 9]

\section{Conclusions}




\section{ACCEPTED MANTISCRIP}

The study found that an optimal mixture of $1.5 \mathrm{mM}$ Triton X-114 and $1.5 \mathrm{M} \mathrm{MgCl}_{2}$ as the draw solution simultaneously facilitated a high water flux $\left(11.38 \mathrm{~L} /\left(\mathrm{m}^{2} \mathrm{~h}\right)\right)$ and low reverse salt flux $\left(2.03 \mathrm{~g} /\left(\mathrm{m}^{2} \mathrm{~h}\right)\right)$. The SMB-OsMBR hybrid system showed excellent ability to remove ammonium (approximately 100\%) and phosphorus (>98\%) in single reactor. This was particularly the case when an ideal attached-growth medium (sponge) provided free mobile carriers for combining the active biomass with the OsMBR system. Furthermore, during the 90-day operation the hybrid system achieved a stable water flux of $10.58 \mathrm{~L} /\left(\mathrm{m}^{2} \mathrm{~h}\right)$ and low membrane fouling because most of the bacterial community was attached to the sponge carriers rather than the FO membrane.

\section{Acknowledgement}

This work was supported by the Ministry of Science and Technology of the Republic of China under the grant number of 101-2221-E-027 -061 -MY3.

\section{References}

Achilli, A., Cath, T.Y., Marchand, E.A. and Childress, A.E. (2009) The forward osmosis membrane bioreactor: A low fouling alternative to MBR processes. Desalination 239(1-3), 10-21.

Bao, L.1., Li, D., Li, X.k., Huang, R.x., Zhang, J., Lv, Y. and Xia, G.q. (2007) Phosphorus accumulation by bacteria isolated from a continuous-flow two-sludge system. Journal of Environmental Sciences 19(4), 391-395.

Bradford and Bradford, M.M. (1976) A rapid and sensitive method for the quantitation of microgram quantities of protein utilizing the principle of protein-dye binding. Anal. Biochem 72, 248-254.

Cornelissen, E.R., Harmsen, D., Beerendonk, E.F., Qin, J.J., de Korte, K.F. and Kappelhof, J.W.M.N. (2011) The innovative Osmotic Membrane Bioreactor (OMBR) for reuse of wastewater. Water Science \& Technology 63(8), 1557-1565.

DuBois, M., Gilles, K.A., Hamilton, J.K., Rebers, P.A. and Smith, F. (1956) Colorimetric Method for Determination of Sugars and Related Substances. Analytical Chemistry 28(3), 350-356.

Ge, Q., Su, J., Amy, G.L. and Chung, T.-S. (2012) Exploration of polyelectrolytes as draw solutes in forward osmosis processes. Water Research 46(4), 1318-1326.

Guo, W., Ngo, H.-H. and Li, J. (2012) A mini-review on membrane fouling. Bioresource Technology 122, 27-34.

Guo, W., Ngo, H.H., Vigneswaran, S., Xing, W. and Goteti, P. (2008) A Novel Sponge Submerged Membrane Bioreactor (SSMBR) for Wastewater Treatment and Reuse. Separation Science and Technology 43(2), 273-285.

Gwak, G., Jung, B., Han, S. and Hong, S. (2015) Evaluation of poly (aspartic acid sodium salt) as a draw solute for forward osmosis. Water Research 80, 294-305.

Holloway, R.W., Wait, A.S., Fernandes da Silva, A., Herron, J., Schutter, M.D., Lampi, K. and Cath, T.Y. (2014) Long-term pilot scale investigation of novel hybrid ultrafiltration-osmotic membrane bioreactors. Desalination 363, 64-74.

Jin, X., Shan, J., Wang, C., Wei, J. and Tang, C.Y. (2012) Rejection of pharmaceuticals by forward osmosis membranes. Journal of Hazardous Materials 227-228(0), 55-61. 
Kim, S. (2014) Scale-up of osmotic membrane bioreactors by modeling salt accumulation and draw solution dilution using hollow-fiber membrane characteristics and operation conditions. Bioresource Technology 165(0), 88-95.

Kiriukhin, M.Y. and Collins, K.D. (2002) Dynamic hydration numbers for biologically important ions. Biophysical Chemistry 99(2), 155-168.

Kiso, Y. (1986) Factors affecting adsorption of organic solutes on cellulose acetate in an aqueous solution system. Chromatographia 22(1-6), 55-58.

Lay, W.C.L., Zhang, Q., Zhang, J., McDougald, D., Tang, C., Wang, R., Liu, Y. and Fane, A.G. (2011) Study of integration of forward osmosis and biological process: Membrane performance under elevated salt environment. Desalination 283, 123-130.

Mi, B. and Elimelech, M. (2008) Chemical and physical aspects of organic fouling of forward osmosis membranes. Journal of Membrane Science 320(1-2), 292-302.

Moussa, M.S., Sumanasekera, D.U., Ibrahim, S.H., Lubberding, H.J., Hooijmans, C.M., Gijzen, H.J. and Van Loosdrecht, M.C.M. (2006) Long term effects of salt on activity, population structure and floc characteristics in enriched bacterial cultures of nitrifiers. Water Research 40(7), 1377-1388.

Nguyen, H.T., Chen, S.-S., Nguyen, N.C., Ngo, H.H., Guo, W. and Li, C.-W. (2015a) Exploring an innovative surfactant and phosphate-based draw solution for forward osmosis desalination. Journal of Membrane Science 489, 212-219.

Nguyen, H.T., Nguyen, N.C., Chen, S.-S., Li, C.-W., Hsu, H.-T. and Wu, S.-Y. (2015b) Innovation in Draw Solute for Practical Zero Salt Reverse in Forward Osmosis Desalination. Industrial \& Engineering Chemistry Research 54(23), 6067-6074.

Nguyen, T.T., Ngo, H.H., Guo, W., Listowski, A. and Li, J.X. (2012) Evaluation of sponge tray-membrane bioreactor (ST-MBR) for primary treated sewage effluent treatment. Bioresource Technology 113, 143-147.

Osaka, T., Shirotani, K., Yoshie, S. and Tsuneda, S. (2008) Effects of carbon source on denitrification efficiency and microbial community structure in a saline wastewater treatment process. Water Research 42(14), 3709-3718.

Park, S.H., Park, B., Shon, H.K. and Kim, S. (2015) Modeling full-scale osmotic membrane bioreactor systems with high sludge retention and low salt concentration factor for wastewater reclamation. Bioresource Technology 190, 508-515.

Qiu, G. and Ting, Y.P. (2013) Osmotic membrane bioreactor for wastewater treatment and the effect of salt accumulation on system performance and microbial community dynamics. Bioresource Technology 150, 287-297.

Qiu, G. and Ting, Y.P. (2014) Direct phosphorus recovery from municipal wastewater via osmotic membrane bioreactor (OMBR) for wastewater treatment. Bioresource Technology 170, 221-229.

Ramesh, A., Lee, D.J., Wang, M.L., Hsu, J.P., Juang, R.S., Hwang, K.J., Liu, J.C. and Tseng, S.J. (2006) Biofouling in Membrane Bioreactor. Separation Science and Technology 41(7), 1345-1370.

Sayi-Ucar, N., Sarioglu, M., Insel, G., Cokgor, E.U., Orhon, D. and van Loosdrecht, M.C.M. (2015) Long-term study on the impact of temperature on enhanced biological phosphorus and nitrogen removal in membrane bioreactor. Water Research 84, 8-17.

Tan, J.-M., Qiu, G. and Ting, Y.-P. (2015) Osmotic membrane bioreactor for municipal wastewater treatment and the effects of silver nanoparticles on system performance. Journal of Cleaner Production 88(0), 146-151.

Uygur, A. (2006) Specific nutrient removal rates in saline wastewater treatment using sequencing batch reactor. Process Biochemistry 41(1), 61-66.

Valladares Linares, R., Yangali-Quintanilla, V., Li, Z. and Amy, G. (2012) NOM and TEP fouling of a forward osmosis (FO) membrane: Foulant identification and cleaning. Journal of Membrane Science 421-422(0), 217-224. 
Wang, X.M. and Li, X.Y. (2008) Accumulation of biopolymer clusters in a submerged

\section{7} membrane bioreactor and its effect on membrane fouling. Water Research 42(4-5), 855-862.

Xiao, D., Tang, C.Y., Zhang, J., Lay, W.C.L., Wang, R. and Fane, A.G. (2011) Modeling salt accumulation in osmotic membrane bioreactors: Implications for FO membrane selection and system operation. Journal of Membrane Science 366(1-2), 314-324.

Xie, M., Nghiem, L.D., Price, W.E. and Elimelech, M. (2012 (a)) Comparison of the removal of hydrophobic trace organic contaminants by forward osmosis and reverse osmosis. Water Research 46(8), 2683-2692.

Xie, M., Price, W.E. and Nghiem, L.D. (2012(b)) Rejection of pharmaceutically active compounds by forward osmosis: Role of solution $\mathrm{pH}$ and membrane orientation. Separation and Purification Technology 93(0), 107-114.

Ye, L., Peng, C.-y., Tang, B., Wang, S.-y., Zhao, K.-f. and Peng, Y.-z. (2009) Determination effect of influent salinity and inhibition time on partial nitrification in a sequencing batch reactor treating saline sewage. Desalination 246(1-3), 556-566.

Zhang, J., Loong, W.L.C., Chou, S., Tang, C., Wang, R. and Fane, A.G. (2012) Membrane biofouling and scaling in forward osmosis membrane bioreactor. Journal of Membrane Science 403-404(0), 8-14 
479 Figure 1. A schematic of the laboratory scale SMB - OsMBR system.

480 Figure 2. Comparison of reverse salt flux and water flux with addition of Triton X-114 into

$481 \mathrm{MgCl}_{2}$ draw solution (active layer facing the feed solution, flow rate of $500 \mathrm{~mL} / \mathrm{min}$, using DI

482 water as feed solution). Error bars were based on the standard deviations of three replicate tests.

483 Figure 3. Schematic illustration of reduced back diffusion of anions and cations with

484 presence of non-ionic surfactant Triton X-114 during FO (Nguyen et al. 2015a, Nguyen et al. 485 2015b).

486 Figure 4. (a) Water flux of the SMB-OsMBR hybrid system versus time, (b) Salt

487 accumulation in the bioreactor during the operation of the SMB-OsMBR hybrid system. Draw

488 solution: $1.5 \mathrm{M} \mathrm{MgCl}_{2}$ coupled with $1.5 \mathrm{mM}$ Triton X-114; feed solution: synthetic

489 wastewater; flow rate of draw solution: $500 \mathrm{~mL} / \mathrm{min}$; membrane orientation: active layer

490 facing the feed solution.

491 Figure 5. Microbial community attached to the sponge carrier and FO membrane during the 492 operation of the SMB-OsMBR hybrid system.

493 Figure 6. Nutrient removal efficiency during the operation of SMB-OsMBR hybrid system.

494 Figure 7. SEM micrographs of the FO membrane: (a) active layer of the original membrane,

495 (b) active layer of the used membrane, (c) EDS image of support layer of used membrane.

496 Draw solution: $1.5 \mathrm{M} \mathrm{MgCl}_{2}$ coupled with $1.5 \mathrm{mM}$ Triton X-114; feed solution: synthetic

497 wastewater; flow rate of draw solution: $500 \mathrm{~mL} / \mathrm{min}$; membrane orientation: active layer

498 facing the feed solution.

499 Figure 8. FEEM of (a) standard peak (b) the feed in bioreactor (c) the diluted draw solution.

500 Draw solution: $1.5 \mathrm{M} \mathrm{MgCl}_{2}$ coupled with $1.5 \mathrm{mM}$ Triton X-114; feed solution: synthetic

501 wastewater; flow rate of draw solution: $500 \mathrm{~mL} / \mathrm{min}$; membrane orientation: active layer 502 facing the feed solution.

503 Figure 9. (a) The SMP concentration, (b) EPS concentration of the fouling layer on the FO 504 membrane and the biofilm layer on a biocarrier. 
508 Table 1. Specifications of sponge carrier used in the SMB-OsMBR system.

\begin{tabular}{lll}
\hline Factor & Unit & Value/material \\
\hline Shape & - & Cubic $(1 \times 1 \times 1 \mathrm{~cm})$ \\
Density & $\mathrm{kg} / \mathrm{m}^{3}$ & $28-30$ \\
Tensile strength & $\mathrm{kPa}$ & 150 \\
Specific Surface area & $\left(\mathrm{cm}^{2} / \mathrm{g}\right)$ & 0.91 \\
Weight (10 pieces) & $\mathrm{g}$ & 0.51 \\
Biomass attached on media (after 60 & $(\mathrm{~g}$ biomass/g sponge) & 1.16 \\
days) & & \\
\hline
\end{tabular}


511 Table 2. Osmotic pressure and viscosity of the draw solutions

\begin{tabular}{lcc}
\hline Draw solution & Osmotic pressure, bar & Viscosity, cp \\
\hline $1.5 \mathrm{M} \mathrm{MgCl}_{2}$ only & $107.48 \pm 1.24$ & $1.82 \pm 0.25$ \\
$1.5 \mathrm{M} \mathrm{MgCl}_{2}+0.5 \mathrm{mM}$ Triton X-114 & $108.60 \pm 2.48$ & $1.87 \pm 0.18$ \\
$1.5 \mathrm{M} \mathrm{MgCl}_{2}+1 \mathrm{mM}$ Triton X-114 & $109.34 \pm 1.26$ & $2.15 \pm 0.21$ \\
$1.5 \mathrm{M} \mathrm{MgCl}_{2}+1.5 \mathrm{mM}$ Triton X-114 & $110.75 \pm 2.98$ & $2.48 \pm 0.16$ \\
$1.5 \mathrm{M} \mathrm{MgCl}_{2}+2.5 \mathrm{mM}$ Triton X-114 & $111.20 \pm 3.10$ & $2.57 \pm 0.18$ \\
\hline
\end{tabular}

512 
517

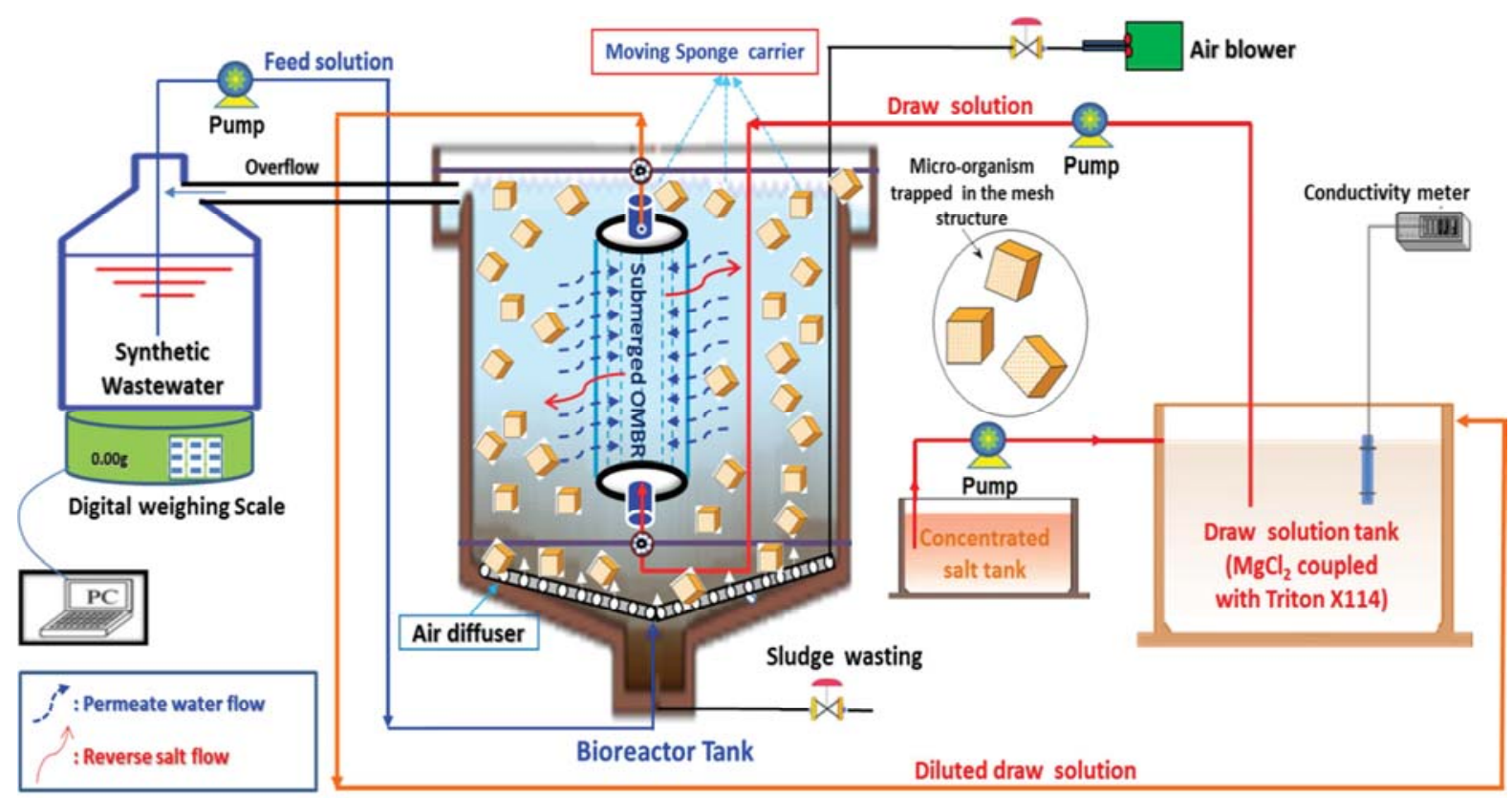

519

520 Figure 1. A schematic of the laboratory scale SMB - OsMBR system. 


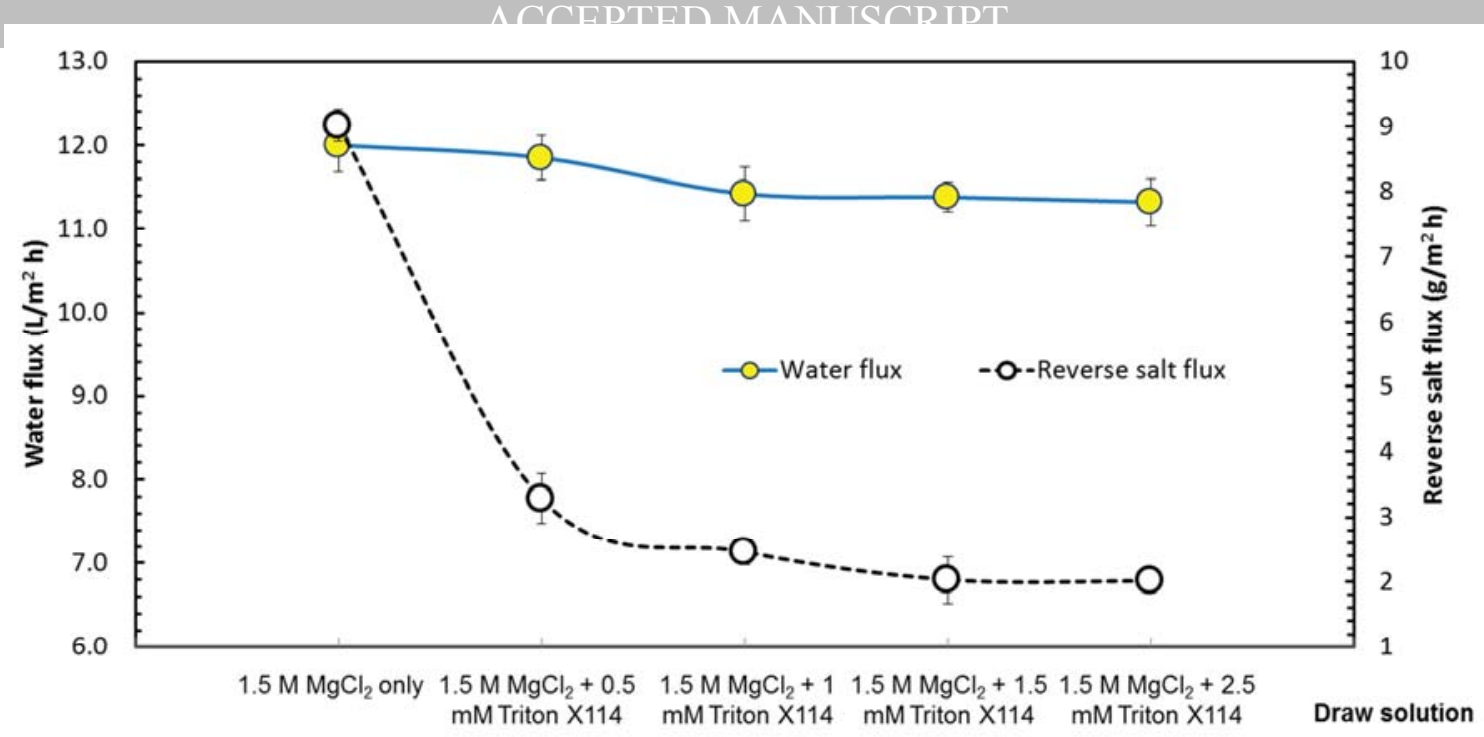

522

523

524

525

526

527

528

529

530

531

532

533

534

535

536

537

538

539

Figure 2. Comparison of reverse salt flux and water flux with addition of Triton X-114 into

$\mathrm{MgCl}_{2}$ draw solution (active layer facing the feed solution, flow rate of $500 \mathrm{~mL} / \mathrm{min}$, using DI water as feed solution). Error bars were based on the standard deviations of three replicate tests.

(1)

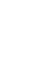

(1)




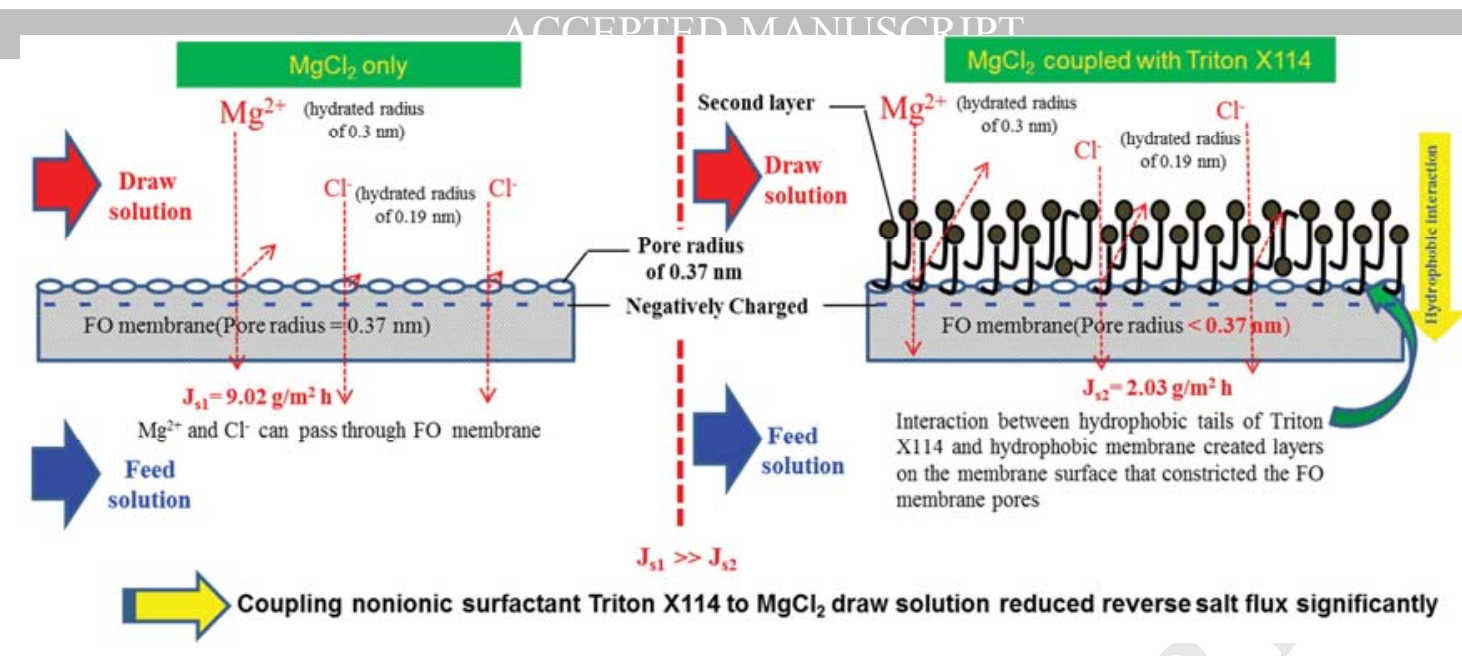

540

Figure 3. Schematic illustration of reduced back diffusion of anions and cations with

542 presence of non-ionic surfactant Triton X-114 during FO (Nguyen et al. 2015a, Nguyen et al.

$5432015 b)$.

544

545 


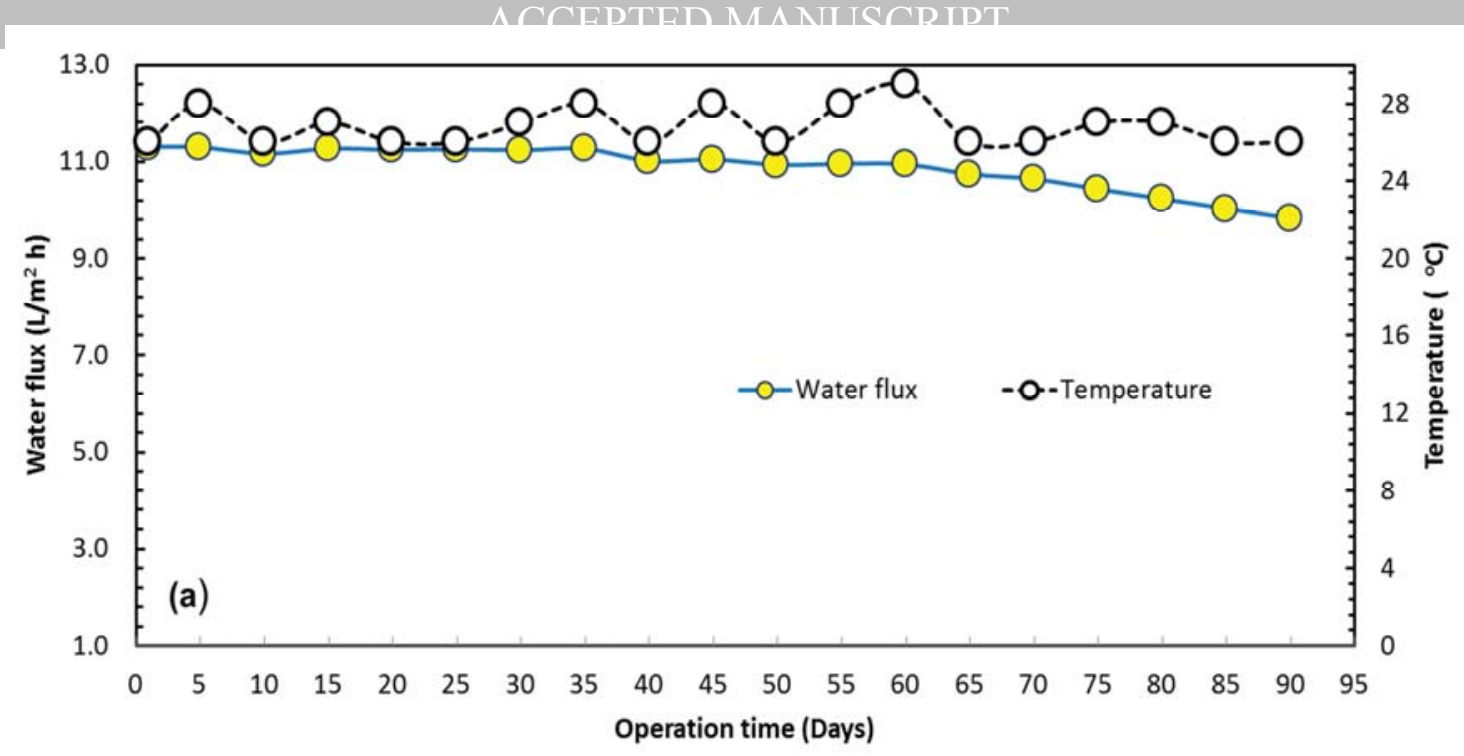

546

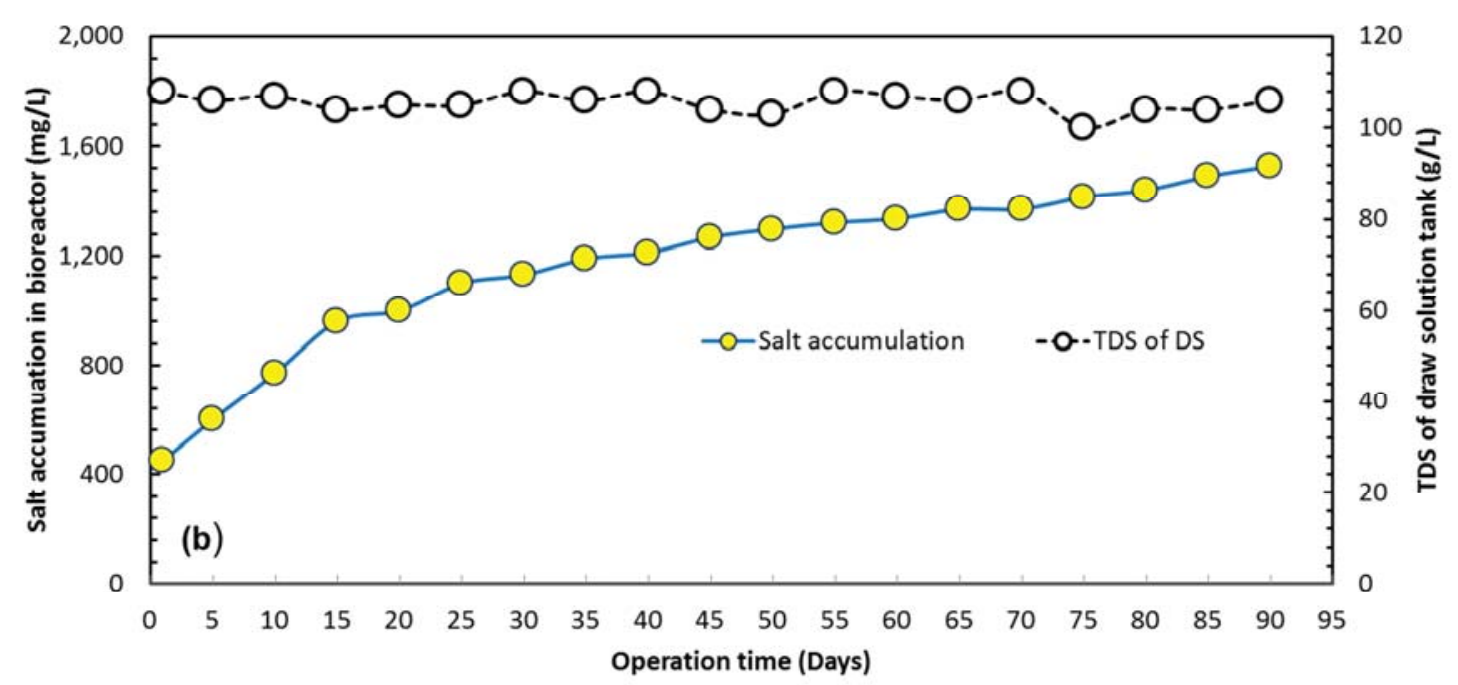

547

548 Figure 4. (a) Water flux of the SMB-OsMBR hybrid system versus time, (b) Salt

549 accumulation in the bioreactor during the operation of the SMB-OsMBR hybrid system. Draw

550 solution: $1.5 \mathrm{M} \mathrm{MgCl}_{2}$ coupled with $1.5 \mathrm{mM}$ Triton X-114; feed solution: synthetic

551 wastewater; flow rate of draw solution: $500 \mathrm{~mL} / \mathrm{min}$; membrane orientation: active layer

552 facing the feed solution. 


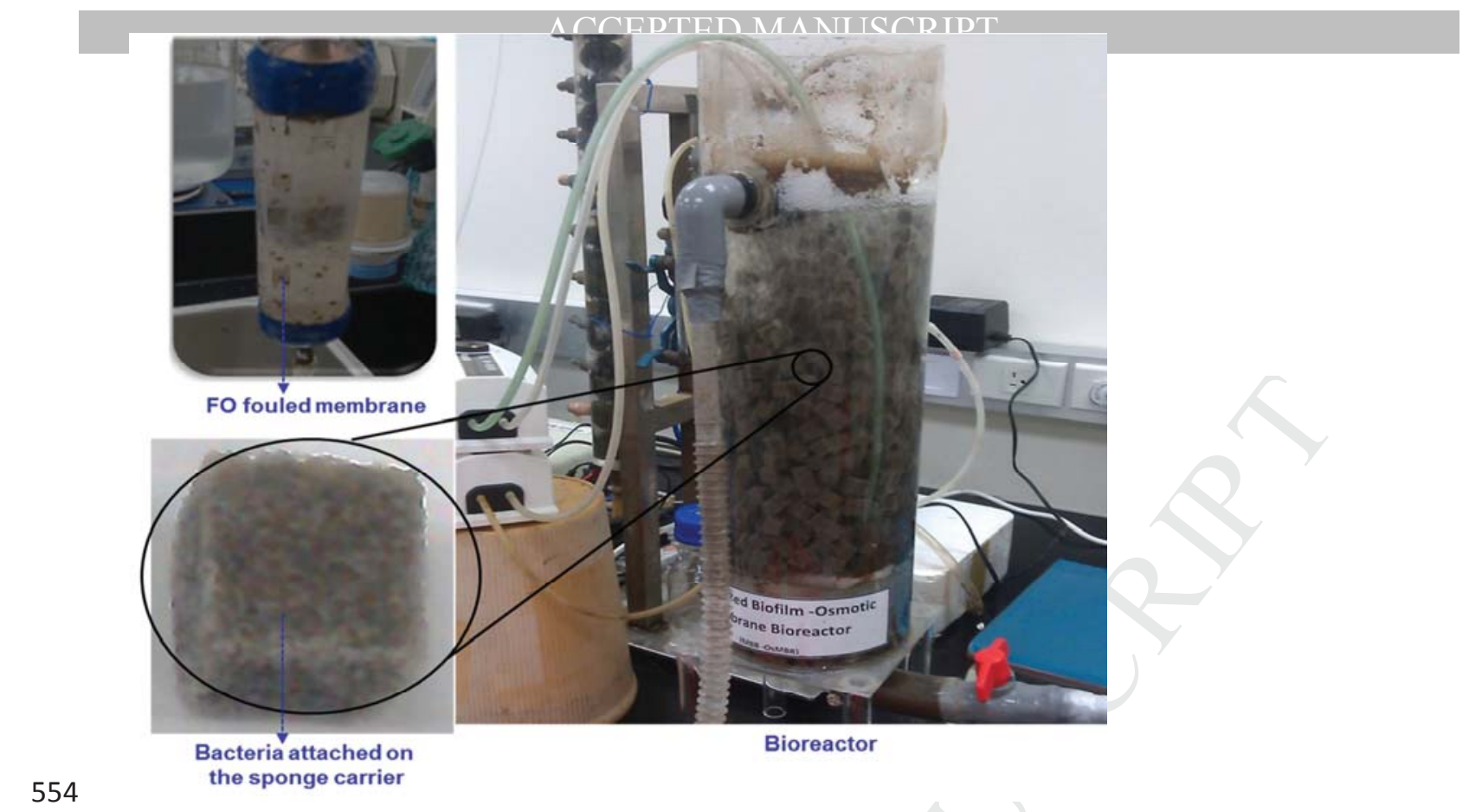

555 Figure 5. Microbial community attached to the sponge carrier and FO membrane during the 556 operation of the SMB-OsMBR hybrid system. 


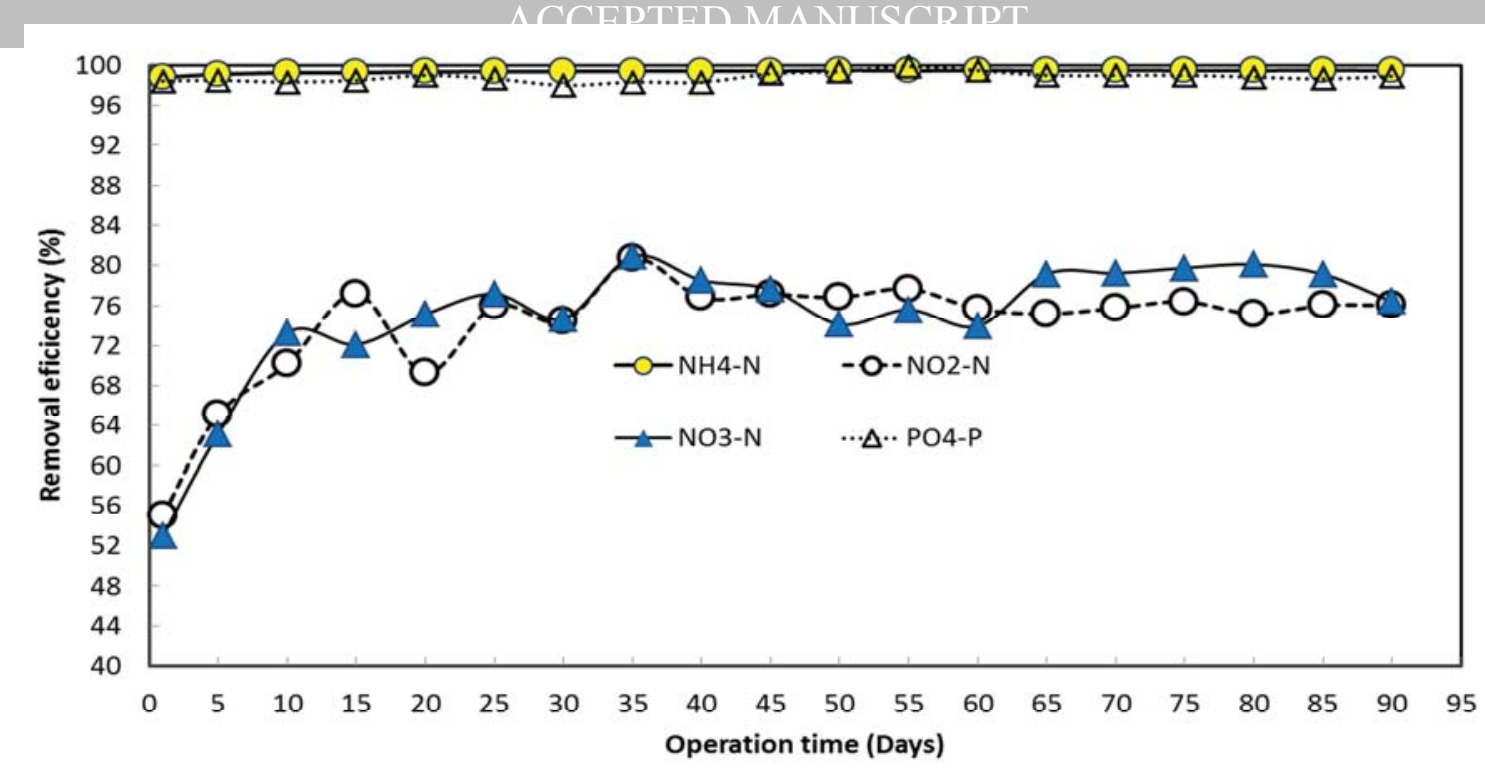

557

558 Figure 6. Nutrient removal efficiency during the operation of SMB-OsMBR hybrid system. 

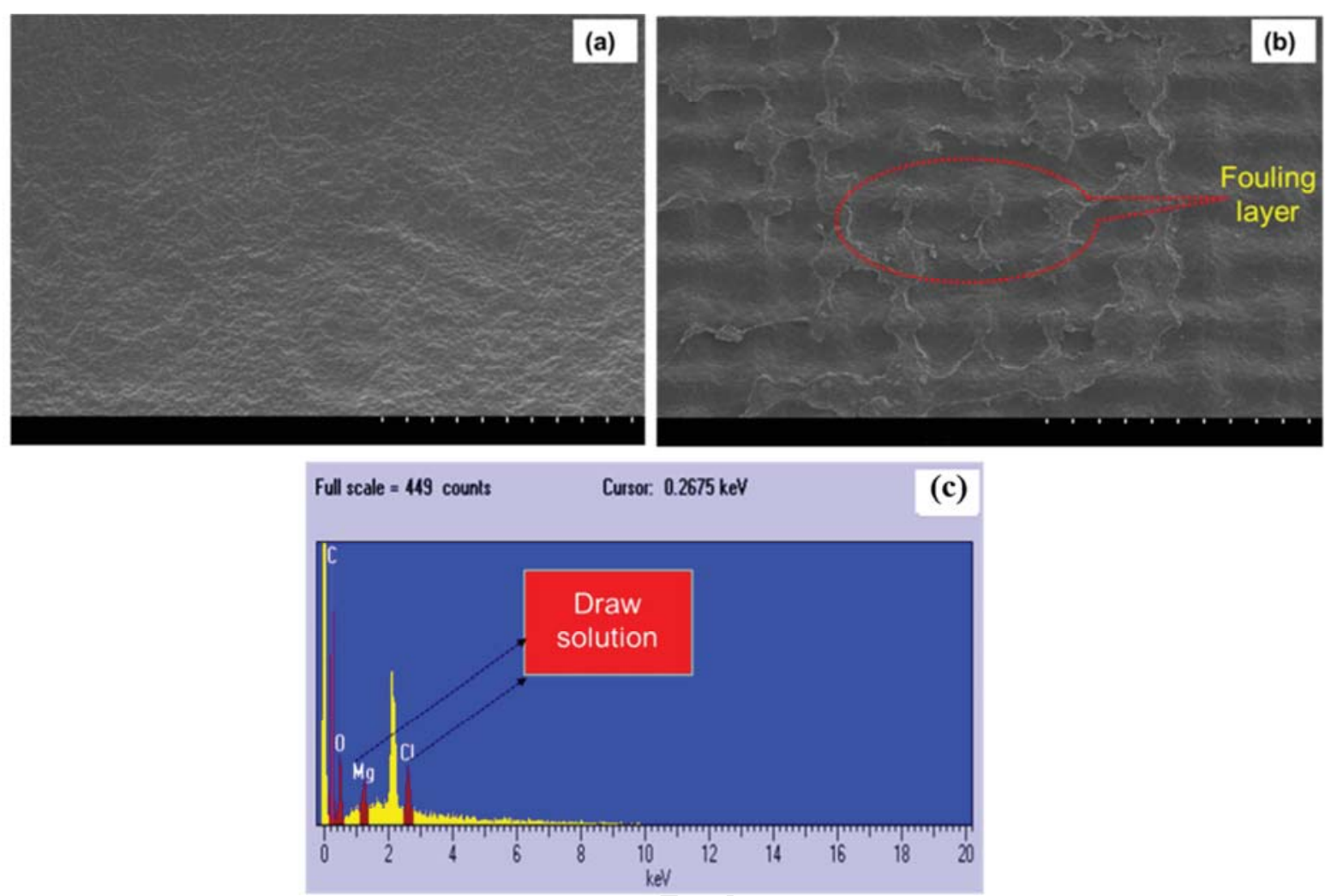

561 Figure 7. SEM micrographs of the FO membrane: (a) active layer of the original membrane,

562 (b) active layer of the used membrane, (c) EDS image of support layer of used membrane.

563 Draw solution: $1.5 \mathrm{M} \mathrm{MgCl}_{2}$ coupled with $1.5 \mathrm{mM}$ Triton X-114; feed solution: synthetic

564 wastewater; flow rate of draw solution: $500 \mathrm{~mL} / \mathrm{min}$; membrane orientation: active layer

565 facing the feed solution. 


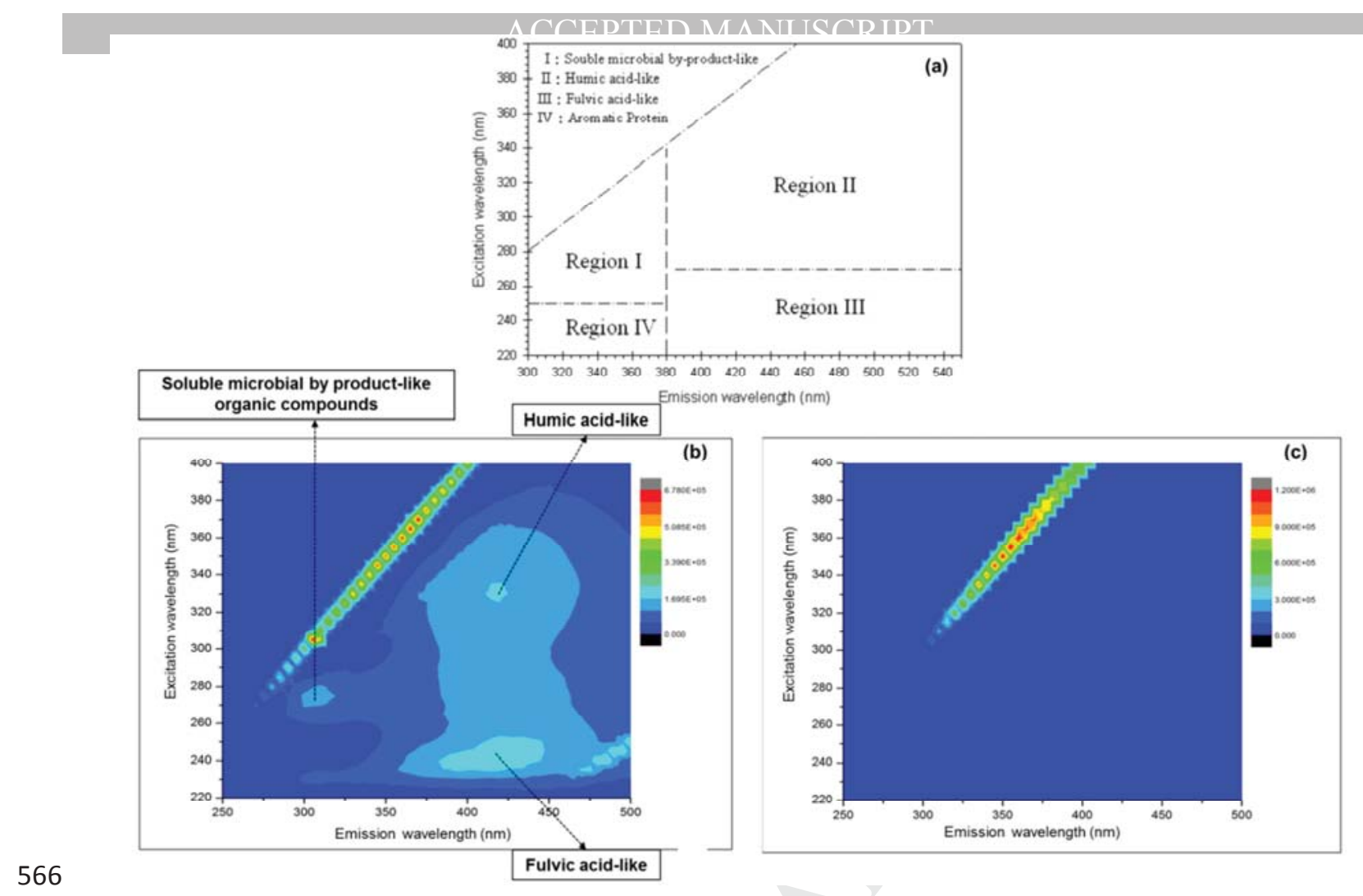

567 Figure 8. FEEM of (a) standard peak (b) the feed in bioreactor (c) the diluted draw solution.

568 Draw solution: $1.5 \mathrm{M} \mathrm{MgCl}_{2}$ coupled with $1.5 \mathrm{mM}$ Triton X-114; feed solution: synthetic

569 wastewater; flow rate of draw solution: $500 \mathrm{~mL} / \mathrm{min}$; membrane orientation: active layer

570 facing the feed solution. 


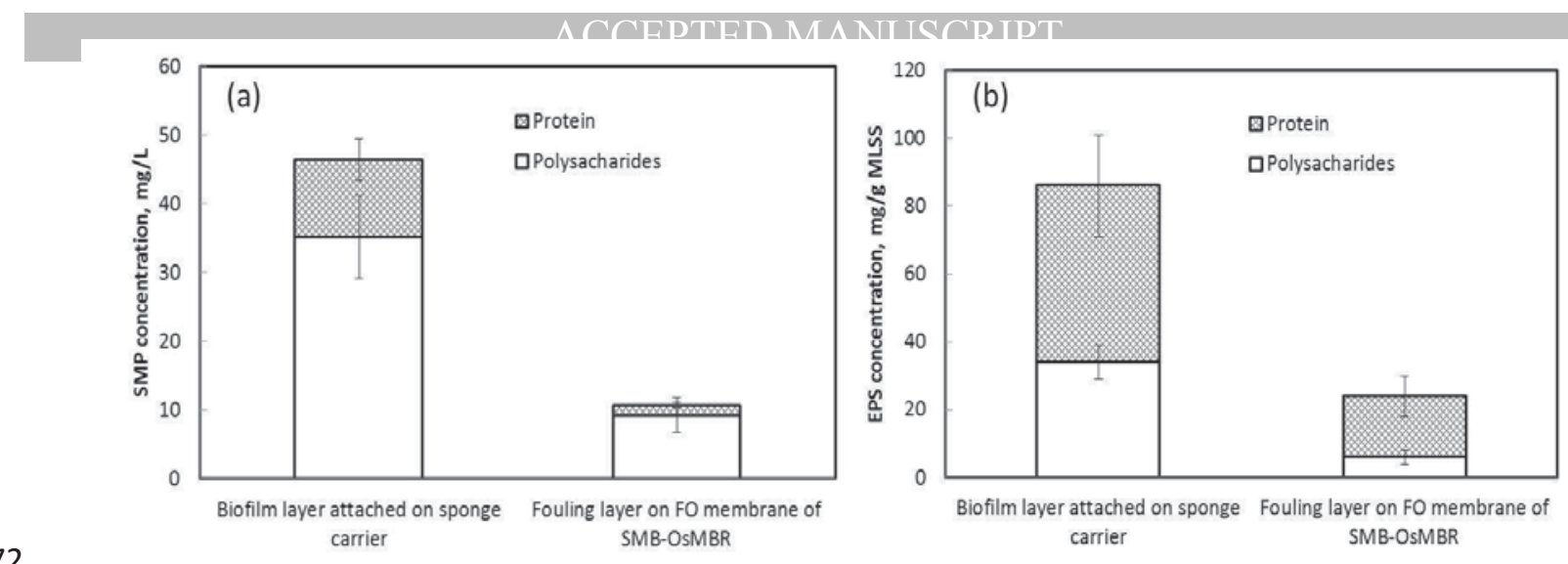

Figure 9. (a) The SMP concentration, (b) EPS concentration of the fouling layer on the FO

574 membrane and the biofilm layer on a biocarrier.

575

576 


\section{Highlights}

* A mixture of $\mathrm{MgCl}_{2}$ and Triton X-114 can serve as a novel draw solution.

* The reverse flux of novel draw solution was 4.5 times lower than that of only $\mathrm{MgCl}_{2}$.

* Low salt accumulation was achieved during 90-day SMB-OsMBR operation.

* Approximately $100 \% \mathrm{NH}_{4}-\mathrm{N}$ and $98 \% \mathrm{PO}_{4}-\mathrm{P}$ were removed by the SMB-OsMBR hybrid system.

* Moving free sponge carriers in the bioreactor continuously cleaned the FO membrane. 